\title{
Research Paper \\ Responses of Endothelin-1 and Arterial Blood Pressure of Postmenopausal Women to Aerobic Exercise Training
}

\author{
*Ahmad Qassemian¹, Farhad Daryanoush ${ }^{1}$, Ebrahim Ghasemian², Elham Shakoor ${ }^{1}$
}

1. Department of Physical Education, Faculty of Education and Psychology, Shiraz University, Shiraz, Iran.

2. Department of Motor Behavior, Faculty of Physical Education, Shahid Rajaee Teacher Training University, Tehran, Iran.

ditation: Qassemian A, Daryanoush F, Ghasemian E, Shakoor E. [Responses of endothelin-1 and arterial blood pressure of postmenopausal women to aerobic exercise training (Persian)]. Iranian Journal of Ageing. 2016; 11(2):368-379. http://dx.crossref.org/10.21859/sija-1102370

http://dx.crossref.org/10.21859/sija-1102370

Received: 13 Mar. 2016

Accepted: 15 Jun. 2016

Key words:

Endothelin-1,

Hypertension

Postmenopausal

women, Aerobic

exercise

\section{A B STRACT}

Objectives Endothelin-1 is a strong constrictor of blood vessels that is secreted by endothelial cells and identified as the strongest vascular constrictor. The aim of the present study was to investigate the effect of eight week aerobic exercise on the endothelin-1 concentration of plasma and its relationship with blood pressure in elderly postmenopausal women.

Methods \& Materials A total of 20 menopausal women (with the average age of $67.85 \pm 5.67$ years, height $153.50 \pm 7.7 \mathrm{~cm}$, weight $66.16 \pm 11.96 \mathrm{~kg}$, BMI of $28.15 \pm 4.98$, fat percentage of $18.41 \pm 3.65$, and WHR of $0.92 \pm 0.04)$ were selected and randomly assigned into two groups of ten each. The experimental group underwent eight weeks of aerobic training spanning across three sessions in a week with the intensity of 60 to $70 \%$ of maximum heart rate. The resting level of endothelin- 1 concentration along with the systolic and diastolic blood pressure for each participant were measured and recorded before and after eight weeks of exercise .Paired t-test was used for investigating the changes within the group while the independent t-test was used for investigating the differences between the groups. Pearson correlation coefficient was used for investigating the relationship between endothelin-1 and blood pressure. A significance level less than 0.05 were considered to be significant.

Results The result of this study showed that one duration of aerobic exercise had a significant effect on endothelin-1 plasma density $(\mathrm{P}<0.01)$ and decreasing systolic $(\mathrm{P}<0.01)$ as well as diastolic $(\mathrm{P}=0.002)$ blood pressure in older women. A direct correlation was established between endothelin-1 and systolic blood pressure $(\mathrm{P}=0.59)$. Nevertheless, no correlation was noted between endothelin-1 and diastolic blood pressure ( $r=0.39)$.

Conclusion It was concluded that single duration of aerobic exercise with the agreed intensity and volume could decrease the systolic and diastolic blood pressure and the endothelin-1 concentration of plasma.

\section{* Corresponding Author:}

Ahmad Qassemian, PhD Candidate

Address: Department of Physical Education, Faculty of Education and Psychology, Shiraz University, Shiraz, Iran.

Tel: +98 (937) 5852913

E-mail: ahmadqassemian@gmail.com 


\title{
ياسخهاى اندوتلين - ا و فشارخون زنان يائسه به تمرينات هوازى
}

\author{
"احمد قاسميان'، فرهاد دريانوش'، ابراهيم قاسميان'، الهام شكور'
}

1- كروه تربيت بدنى و علوم ورزشى، دانشكده علوم تربيتى و روانشئاسى، دانشكاه شيرازه، شيرازٔ، ايران.

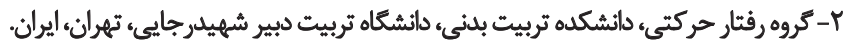

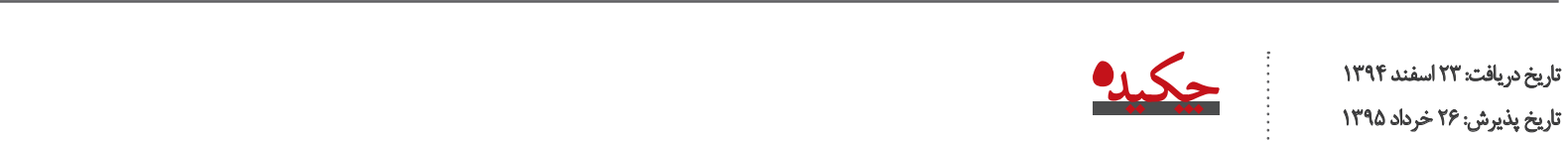

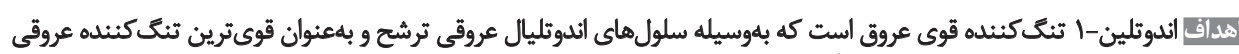

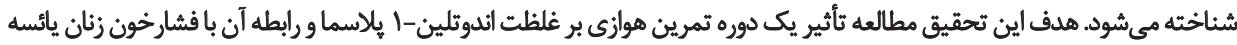

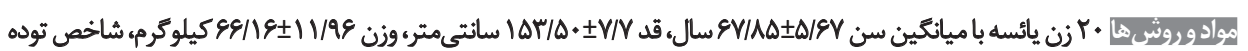

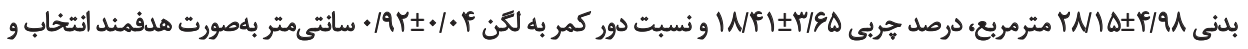

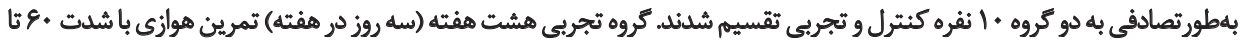

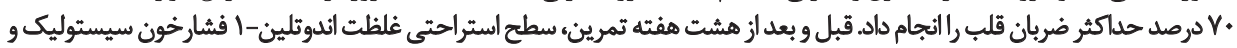

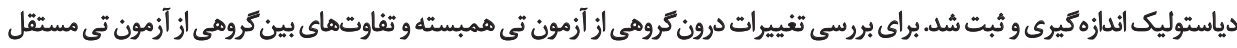

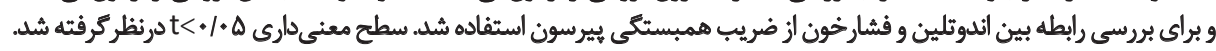

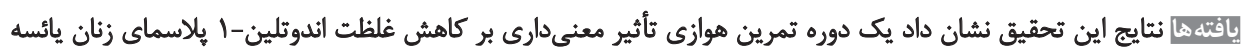

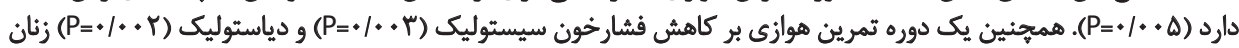

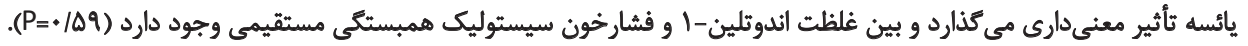

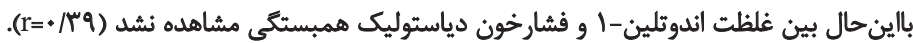

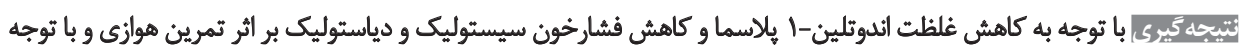

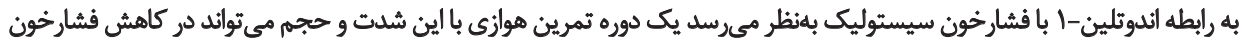

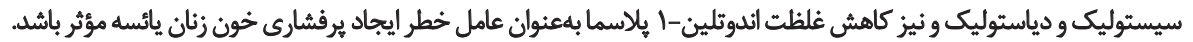

كليدوارهها:

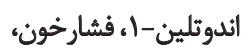

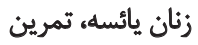
هوازى (ئان
\end{abstract}

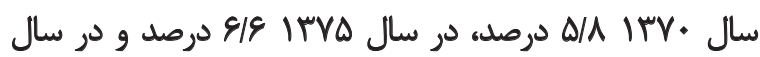

doles هي IrAD

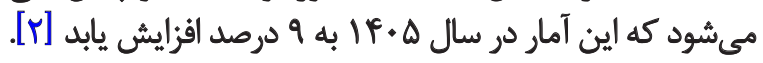
بلهوركلى مشخص شده است فقدان عملكرد مناسب

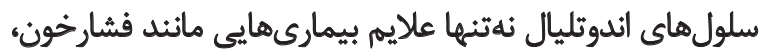

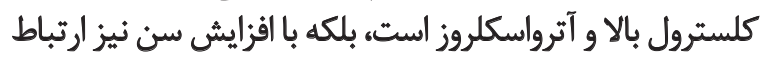

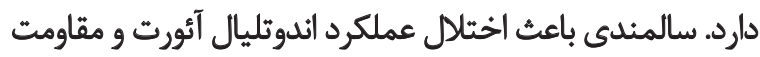

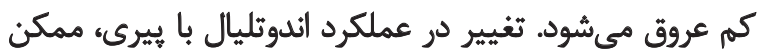

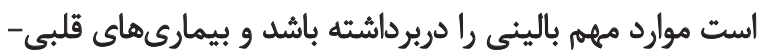

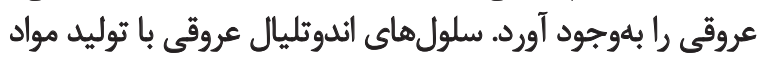

سالمندى بيمارى نيست، بلكه يك فرايند زيستشناختى

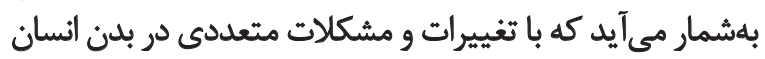

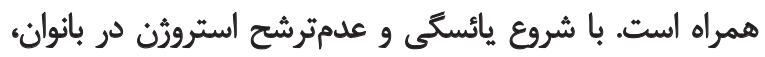

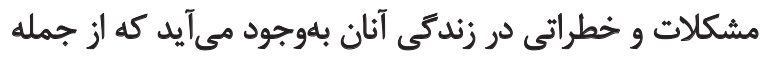

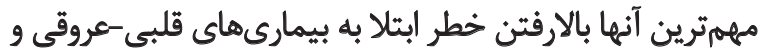

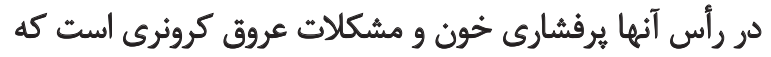

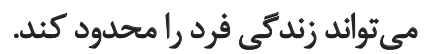
براساس كزارش مركز آمار ايران، جمعيت سالمندان كشور در مرد 


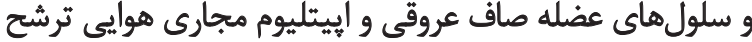

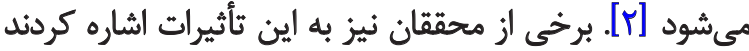

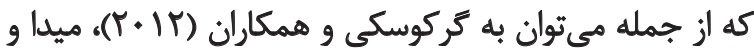

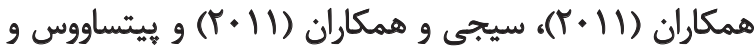

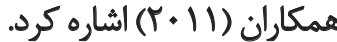

ازآنجايىكه در توليد اندوثلين-1 عوامل مختلف رئولوزيك

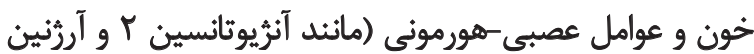

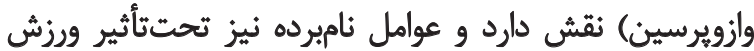

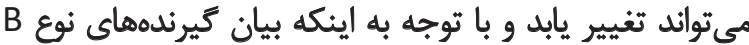

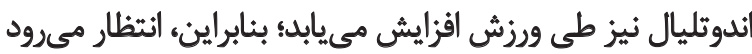

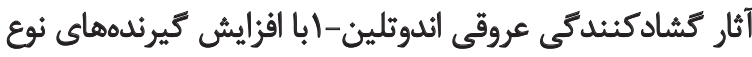

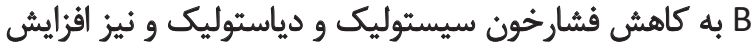

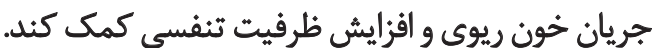

اندوثلين-1 از طريق كيرنده اندوتلين B سلول اندوثليال

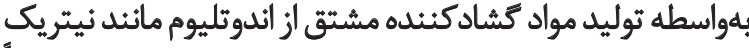

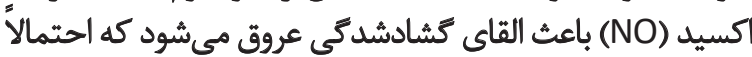

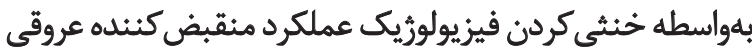

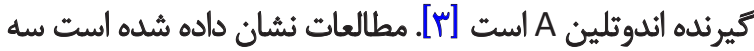

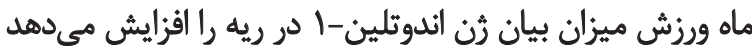

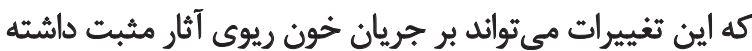

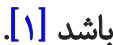

افزيش سن و يرفشارى خون، دو عامل اصلى خطرناك

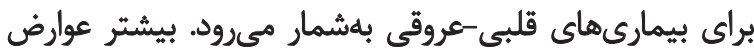

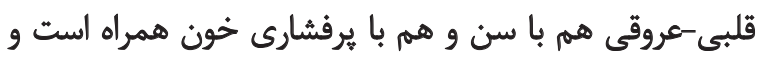

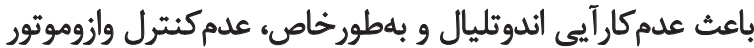

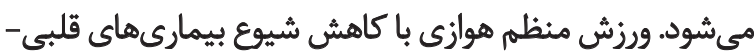

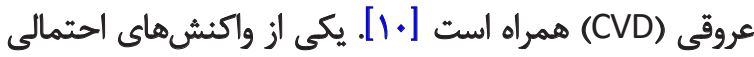

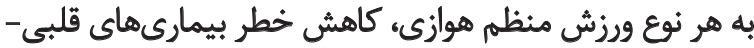

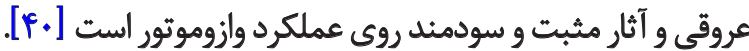

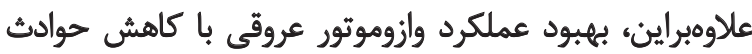

$$
\text { قلبى -عروقى مرتبط است. }
$$

مطالعات متعددى نشان مىدهد ورزش هوازى، گشادشدن

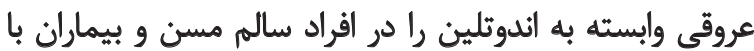

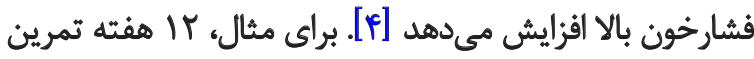

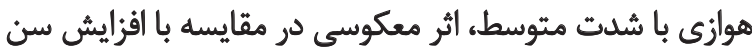

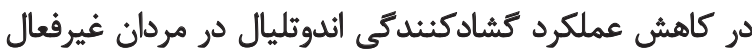

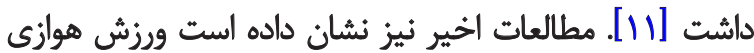

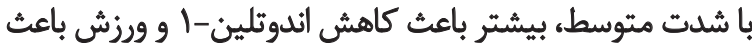

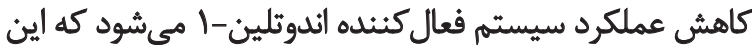

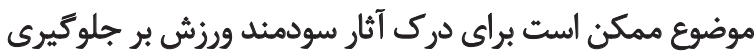

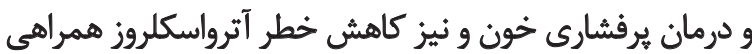

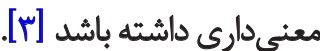

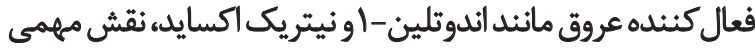
در تنظيم فعاليتهاي عروقى برعهيده دارند [1] اندوتلين 'كه در سال ه1919 توسط ياناكيزاواو ماساكاي كشف كئ

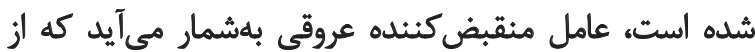

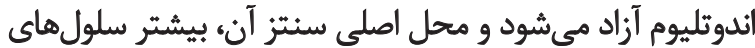

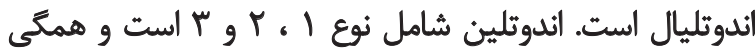

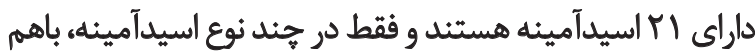

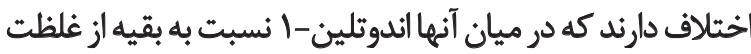
بالاترى برخوردار است.

اندوثلين-ا، تنكگكنيده قوى عروقى است كه بهوسيله

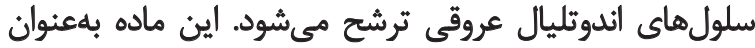

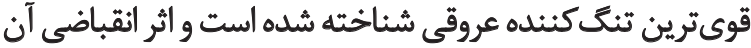

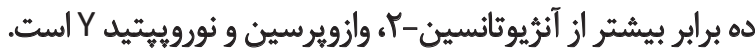

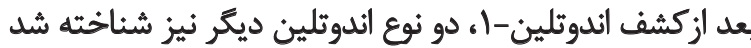

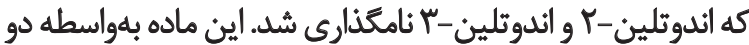

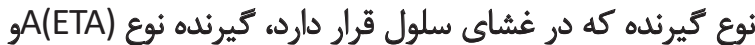

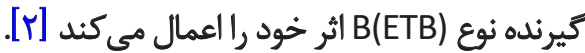
ازطرفديكر، اندوثلين-1 در ايجاد و وبيشرفت آترواسكلروز

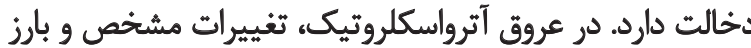

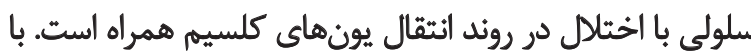

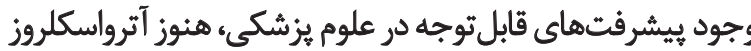

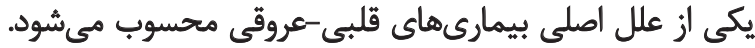

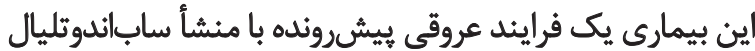

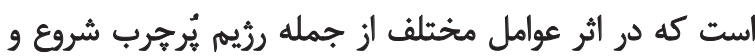

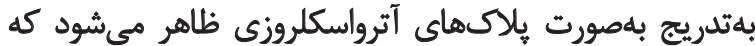

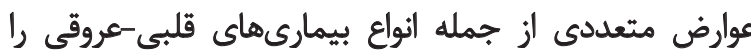

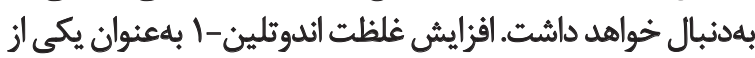

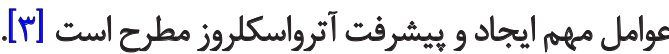
علاوهبراين مشخص شده است فعاليت بدنى و ورزش، باعث

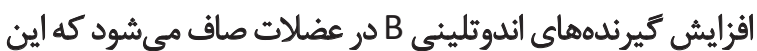

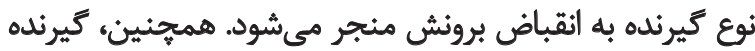

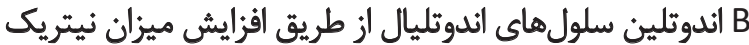

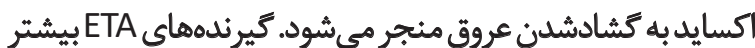

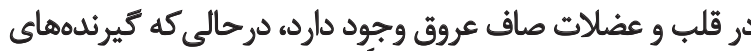

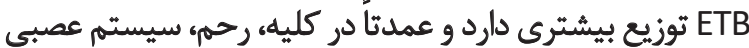

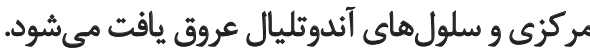

تيرندههاى ETA واسطه اصلى انقباض عروقى بلوسيله

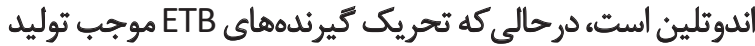

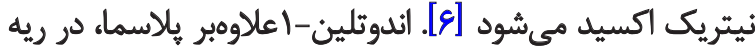

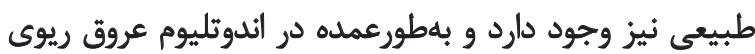




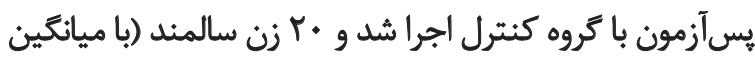
سن

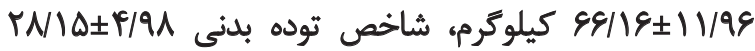

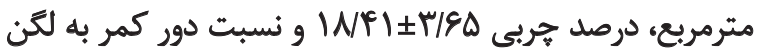

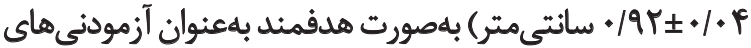
اين تحقيق انتخاب شدند.

آزمودنى هاى منتخب سابقهاى در شركث در تمرينهاى هوازى

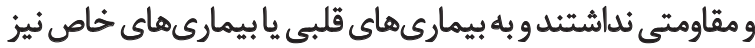

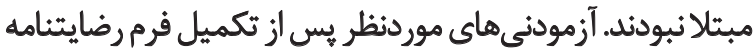

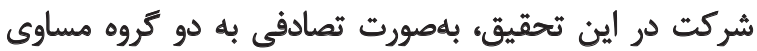

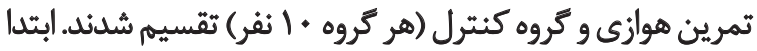

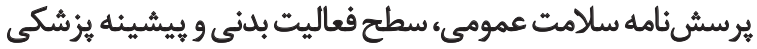

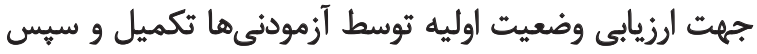

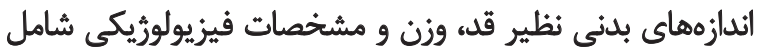

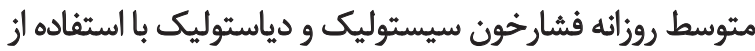

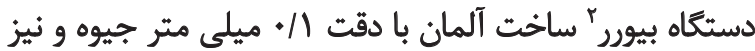

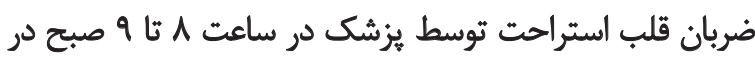

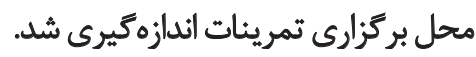

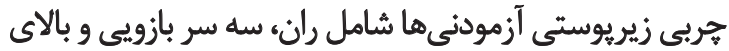

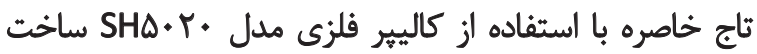

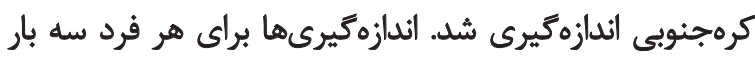

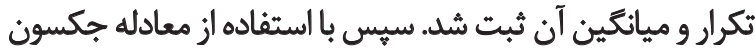

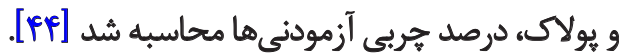

$D b=1.0994921-0 / 0009299 \times S S F+0 / 0000023 \times S_{S F}^{2}-$ 0/0001392×Age

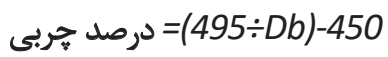

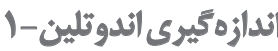

ه

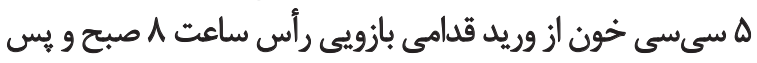

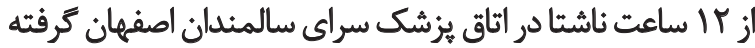

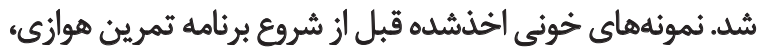

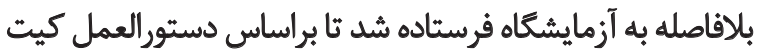

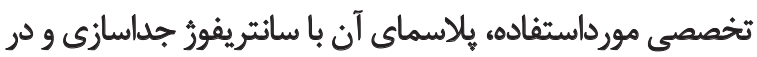

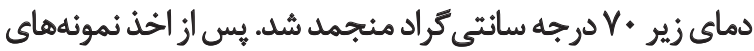

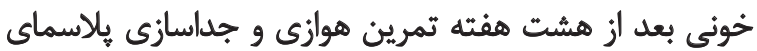

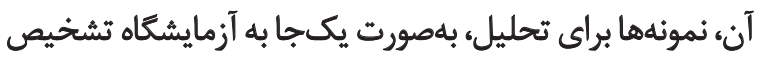

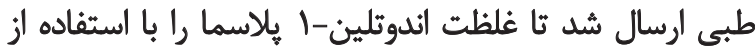

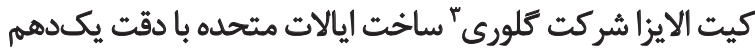

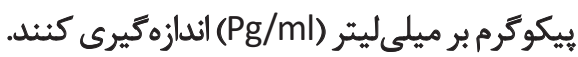

2. Beurer

3. GLORY

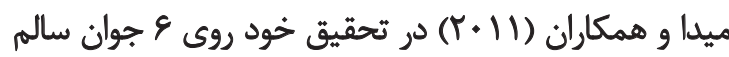

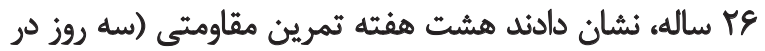

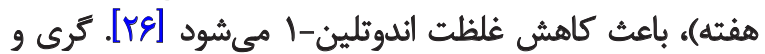

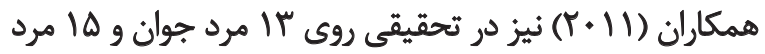

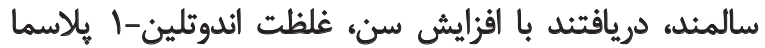

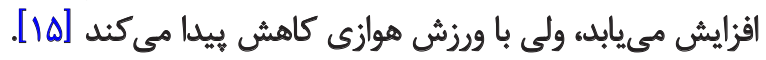

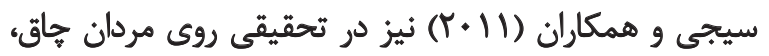

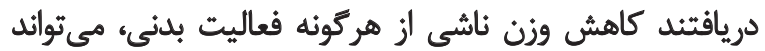

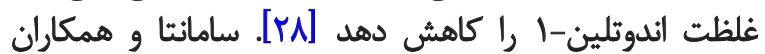

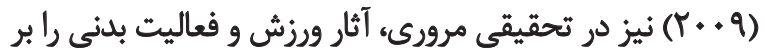

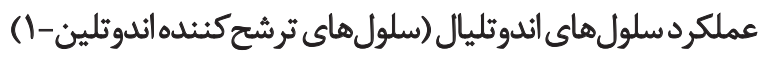

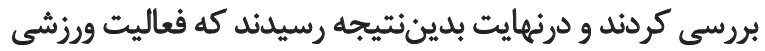

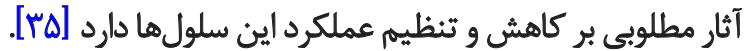

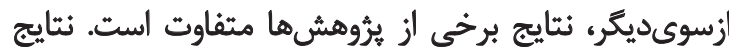

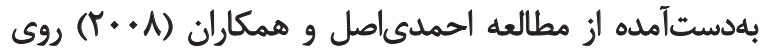

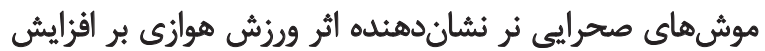

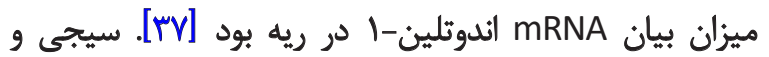

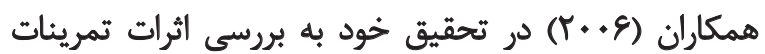

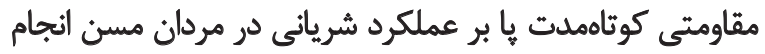

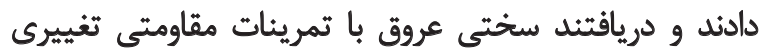
نمى كند.

تراكم اسيدنيتريك هايلاسما (NO) بهعنوان ماده يايدار نمهايي

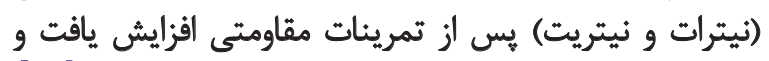

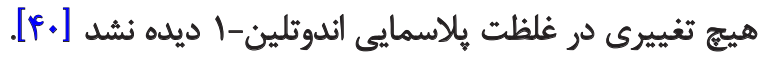

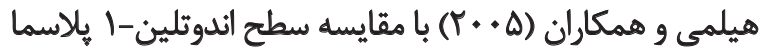

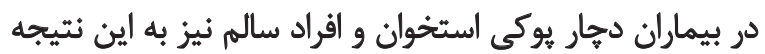

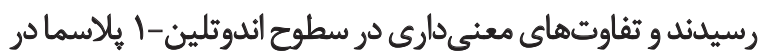
بين كروههاى ورزش و كنترل مشاهده نكردند [19] با توجه به اينكه افراد سالمند بيشترين ميزان ابتلا به فشارخون

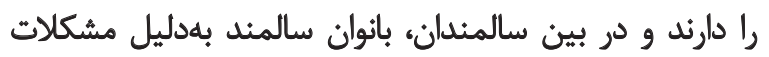

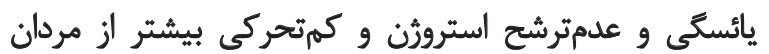

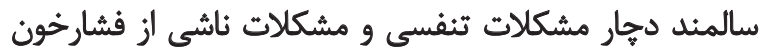

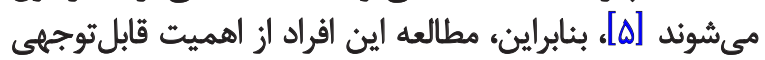

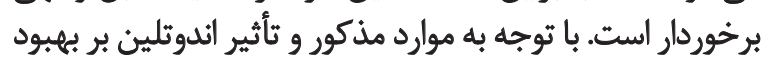

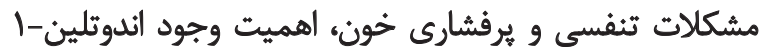

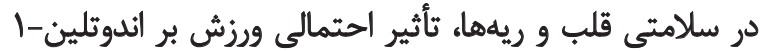

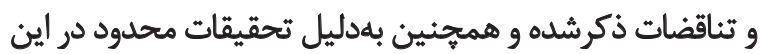

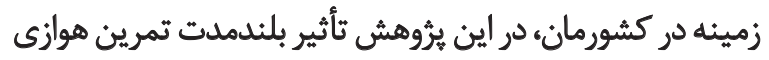

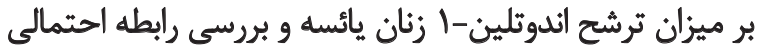

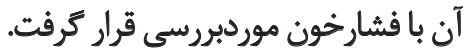

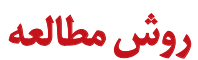

اين تحقيق از نوع نيمهتجربى بود كه بهصورت بيشآزمون- 
استفاده شد. همجنين، نتايج بهدست آمده در سطح معنى دارى كمتر از هـ/ موردبررسى قرار كرفت.

يافتهها

مشخصات بدنى و فيزيولوريكى آزمودنى ها قبل و بعد از هشت

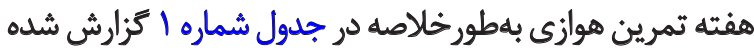

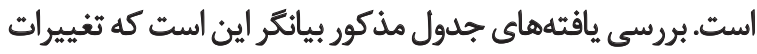

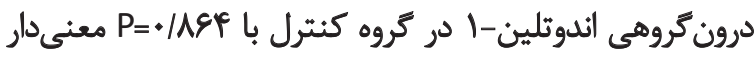

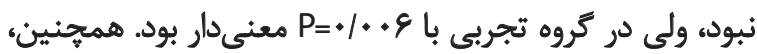

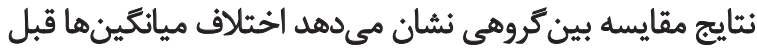

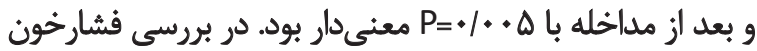

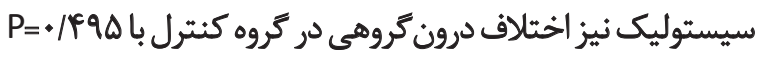

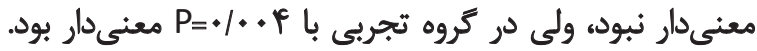

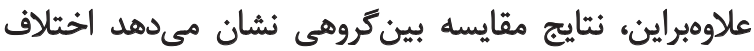

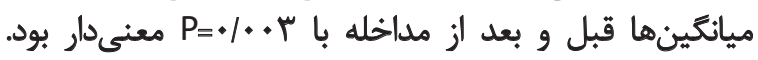

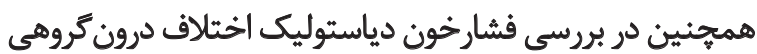

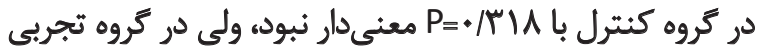

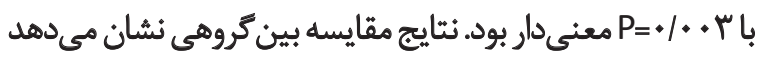

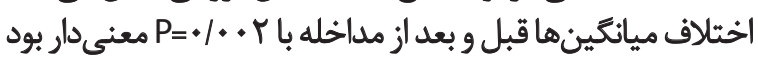

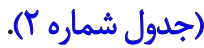

در بررسى رابطه بين متغيرها مشخص شد بين غلظئت

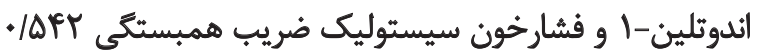

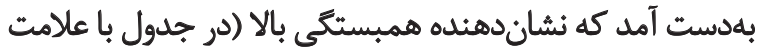

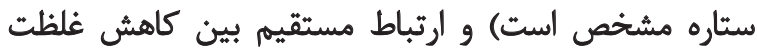

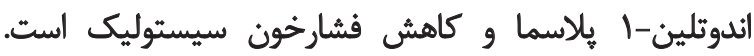

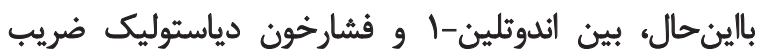

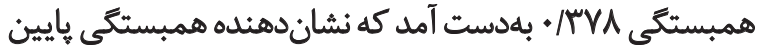

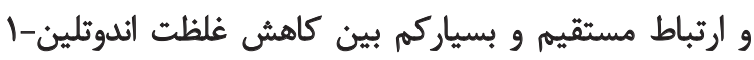
يلاسما و فشارخون دياستوليك است (جدول شماره بار). بحث

نتايج حاصل از اين تحقيق نشان داد هشت هفته تمرين هوازى،

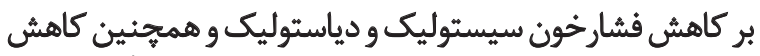

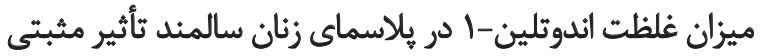

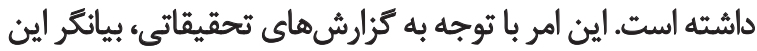

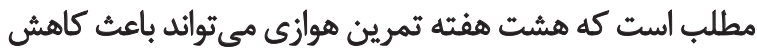

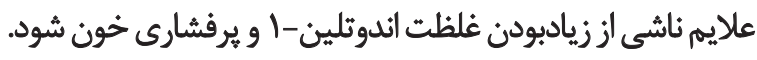
همانطوركه نتايج اين تحقيق نشان داد، هشت هفته تمرين

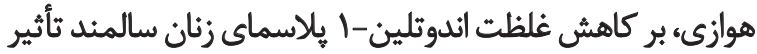

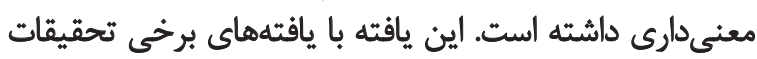

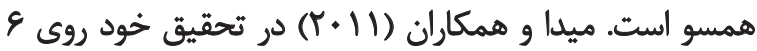

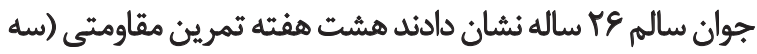

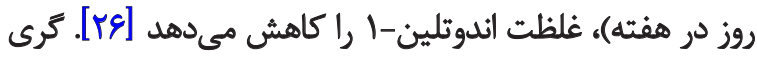

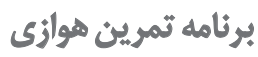

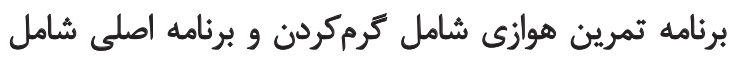

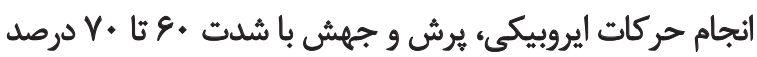

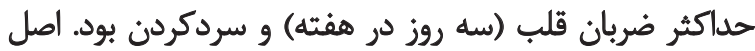

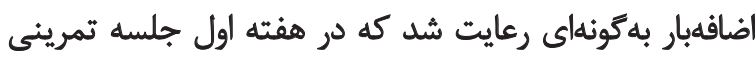

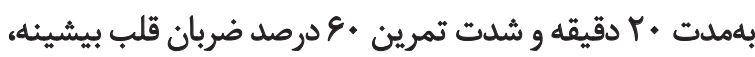

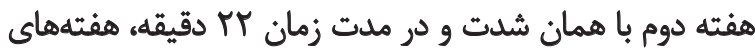

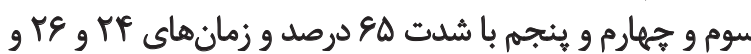

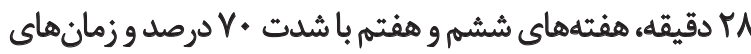

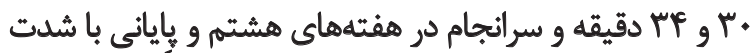

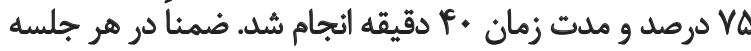

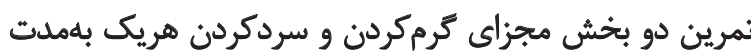
• إديقه صورت بذيرفت.

لازم بلهذكر است كه بروتكل تمرينى اين تحقيق با توجه

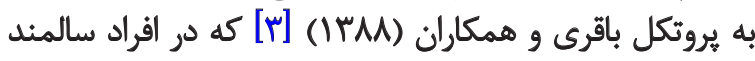

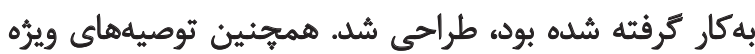

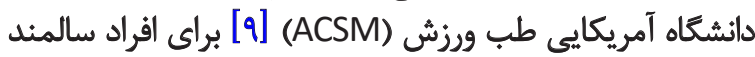

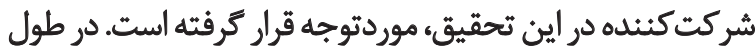

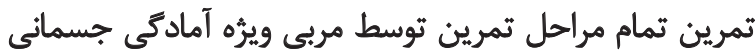

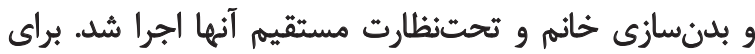

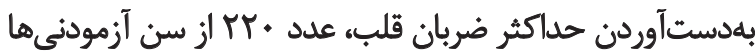

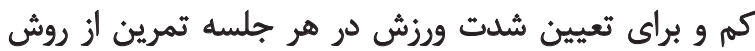

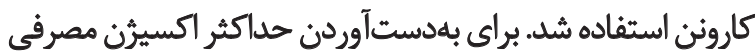
نيز آزمون يك مايل بيادهروى راكيورت مورداستفاده قرار كرفت

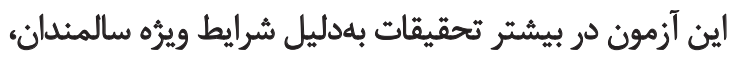

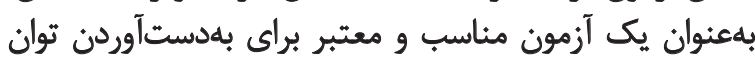

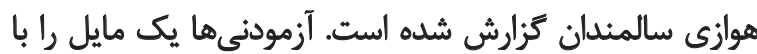

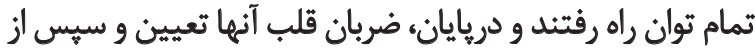
طريق فرمول زير حداكثر اكسيرن مصرفى آنها محاسبه شد آنسان]

$\mathrm{VO}_{2 \max }=$

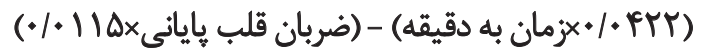

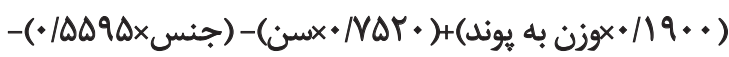

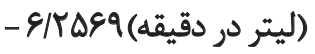

روش تجزئوتحليل دادهها

ميانگين و انحراف استاندارد متغيرهاى موردبررسى با استفاده

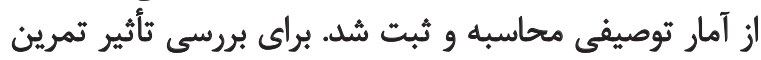

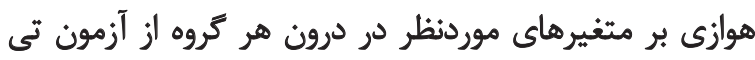

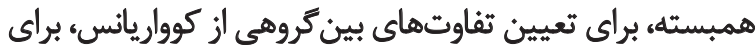

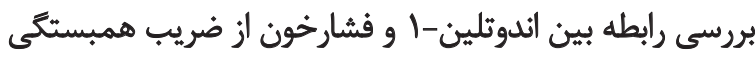

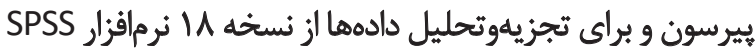


جدول ا. مشخصات بدنى و فيزيولوزيكى آزمودنى هاي موردمطالعه قبل و بعد از مداخله.

\begin{tabular}{|c|c|c|c|c|c|c|}
\hline \multirow{2}{*}{ 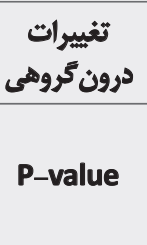 } & \multicolumn{2}{|c|}{ تيروه كنترل } & \multirow{2}{*}{ 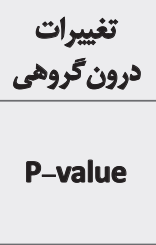 } & \multicolumn{2}{|c|}{ كروه تجريب } & \multirow{2}{*}{ فيزيولوزيكيى بدنى و } \\
\hline & 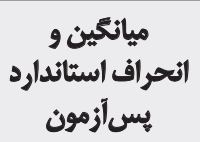 & 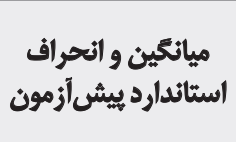 & & 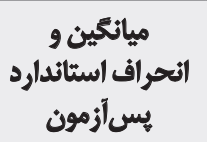 & انحيراف السئاندارد و & \\
\hline- & & EV/RT $\pm \Delta / M T$ & - & & $E N \cdot A \pm E / I Y$ & سن (سال) \\
\hline- & & $\mid Q 1 / q \cdot \pm E / / q$ & - & & $1 \otimes \otimes / 11 \pm 9 / \cdot 1$ & قد (سايتى متر) \\
\hline$=$ & $8 N 1 \cdot \pm 1 \% / \cdot 1$ & $E V /+r \pm I r / \Delta Y$ & $=$ & $8 T / r+1 . / 9$ & $g \Delta / T \pm \mid 1 / P T$ & وزن (كيلوكرم) \\
\hline- & $r q / q \cdot \pm q / q r$ & $r q / M T+E / V D$ & - & $r \Delta / R^{N} \pm r / U$ & $r \varepsilon / u \pm r / r \mid$ & شاخص توده بلني (كيلو كرم بر \\
\hline- & WAVAEY/q. & WAP+EY/QY & - & $|q|+1+ \pm r \mid+r$ & IV/quq \pm t/rA & هربيى (درصد) \\
\hline- & / /QFT. $\pm \cdot / . \mu 1$ & 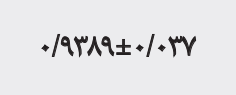 & - & $+|A Y+Y \pm *|+F \mid$ & $\cdot / 9+8+ \pm+1+4 f$ & نسبت دور كمر به لكن \\
\hline- & $V / \cdot 1 \pm r / r$. & $V \cdot|\Lambda| \pm Y / M \mid$ & - & $8 \Delta / \Delta \& \pm 1 / 99$ & ENQY $\pm r / \cdot V$ & ضربان قلب استراحت \\
\hline$\cdot 1 N$ & $\Delta / / \% r \pm \mid \& / 8$. & $\Delta \cdot / 9 \vee \pm 10 / q^{\mu}$ & $.1+\cdot \varphi^{\circ}$ & $r q / / \Delta \pm r+/ q r$ & $g r / R F \pm r r / A \Delta$ & أندوثلين-1) (pg/ml) \\
\hline .10 & ITNAY \pm VAV & $1 r N F q \pm V / M$ & $.1 . p^{e}$ & IYE/TrEII/M & $\mid m / / m+ \pm 10 / N^{\circ}$ & 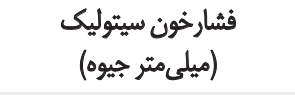 \\
\hline . & $W \cdot r \pm \Delta / \cdot \Lambda$ & $A V / \&+ \pm \Delta / P^{\prime}$ & $.1 .+1$ & $\Lambda \cdot|\&| \pm 1 / \Lambda \Delta$ & $\Lambda \Delta / A \cdot \pm H / \Delta V$ & 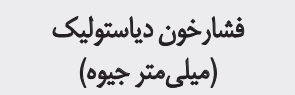 \\
\hline
\end{tabular}

il

جدول r. ميانكين تغييرات بههمراه درصد تغييرات متغيرهاى موردبررسى بين كروههاى تجربى و كنترل.

\begin{tabular}{|c|c|c|c|c|c|c|}
\hline P-value & $\mathbf{t}$ & اختلاف ميانكينها & ميانتّين و اتحراف معيار تغييرات & درصد تغييرات & $\log _{0}$ & مثغير هاى وابسته \\
\hline \multirow{2}{*}{..$+ r$} & \multirow{2}{*}{$r / \varphi}$. & \multirow{2}{*}{ WEA } & $-|N| q \pm 1 ه / r \Delta$ & - YNT & تجريى & \multirow{2}{*}{ ألدوثلين-1 } \\
\hline & & & $+\cdot / \mathscr{E} \pm \mathcal{N} T$ & $++1 A T$ & كتتل & \\
\hline \multirow{2}{*}{.1 .4} & \multirow{2}{*}{ T/QF } & \multirow{2}{*}{$\Delta / \%$} & $-\Delta / \cdot V \pm C / \Delta P$ & $-r / e q$ & تجريى & \multirow{2}{*}{ فشارخون سيستوليك } \\
\hline & & & $+\cdot / M \pm I / F V$ &.$+ / T E$ & كثترل & \\
\hline \multirow{2}{*}{$+1+\infty$} & \multirow{2}{*}{$\mathrm{F} / \mathrm{V}$. } & \multirow{2}{*}{.$/ \Delta E$} & $-+/ \Delta T \pm \cdot / K \varepsilon$ & $-\Delta / 9 r$ & تجريى & \multirow{2}{*}{ فشارخون دياستوليك } \\
\hline & & & $+* / * f \pm * / 1 r$ & $+\cdot(\Delta)$ & كنترل & \\
\hline
\end{tabular}

记

مطلوبى بر كاهش و ثنظيم عملكرد اين سلولها دارد [هب].

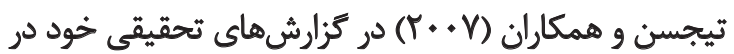

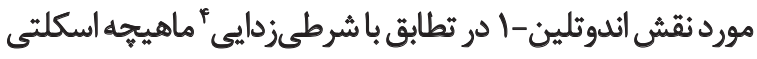

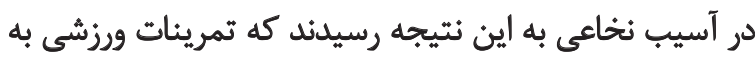
معكوسسازى مسير IFT-

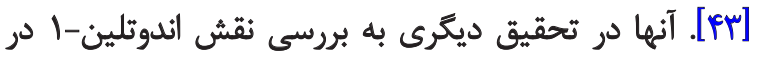

4. A causal role for endothelin-1 in the vascular adaptation to skeletal muscle deconditioning in spinal cord injury

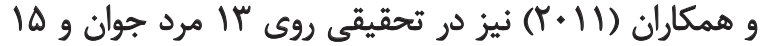

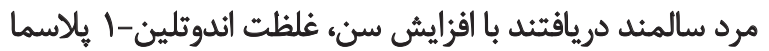

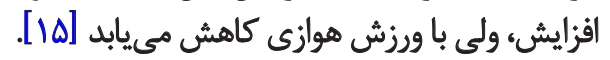

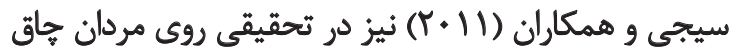

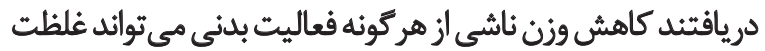

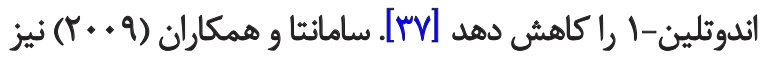

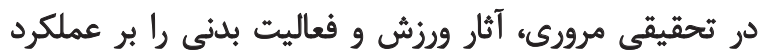

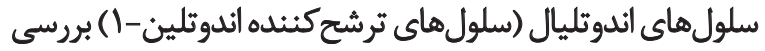

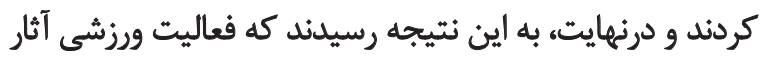


جدول ץ. نتايج آزمون همبستكّى ييرسون.

\begin{tabular}{|c|c|c|c|c|}
\hline قشار خون دياستوليى & فشارخون سيستوليك & أندوثلين-1 & & \\
\hline $\begin{array}{l}+/ 4 q . \\
.11\end{array}$ & $\begin{array}{l}.1 \Delta \mathrm{VA}^{\circ} \\
.1 .1 \mathrm{If}^{\circ}\end{array}$ & $\begin{array}{l}1 \\
-\end{array}$ & همبستكى يبرسون & | \\
\hline $\begin{array}{l}. / \text { me } \\
.1 \cdot 18\end{array}$ & $\begin{array}{l}1 \\
-\end{array}$ & $\begin{array}{l}.10 \mathrm{VA} \\
. / .14\end{array}$ & همبستكي ييرسون & فشارخون سيستوليك \\
\hline $\begin{array}{l}1 \\
-\end{array}$ & $\begin{array}{l}. / 496 \\
.1 \cdot 1 e\end{array}$ & $\begin{array}{l}. / 4 q . \\
. / 1\end{array}$ & معبسكي يير سون & فشارخون دياستوليك \\
\hline
\end{tabular}

L

نيست. نتايج بلهدستآمده از مطالعه احمدى اصل و همكاران

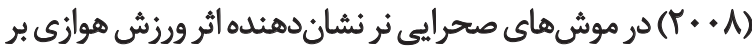

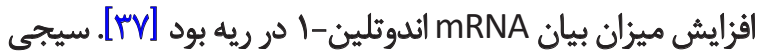

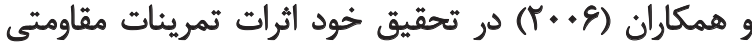

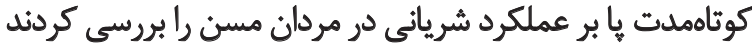

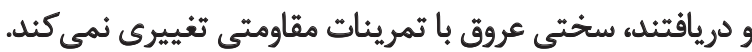

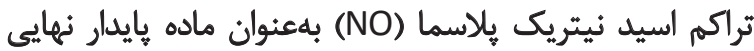

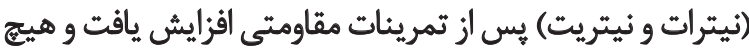

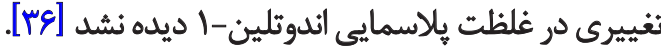

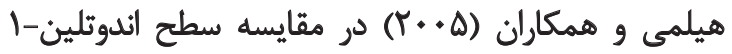

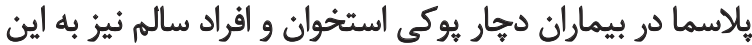

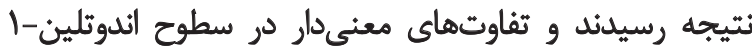

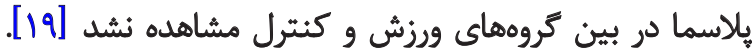

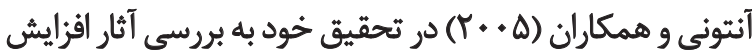

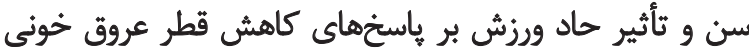

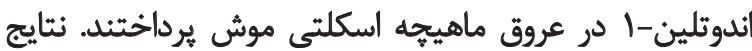

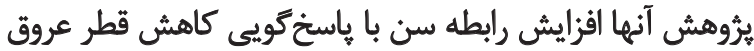

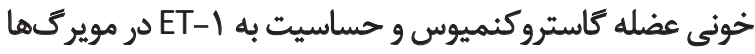

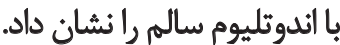

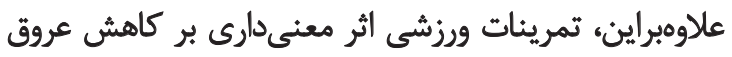

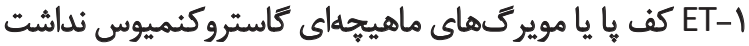

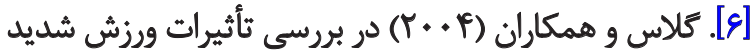

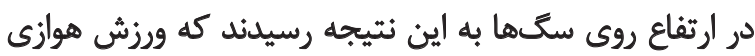

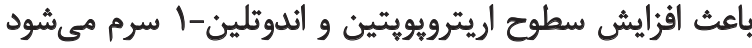

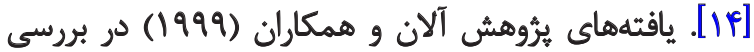

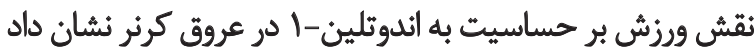

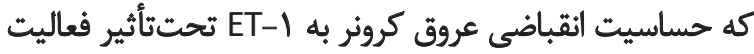

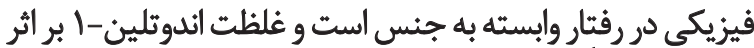
ورزش احتمالاً افزايش مىئه بهابد [هن]. در مطالعهاى ديكر، سيجى و همكاران (991) به عدمتغيير
انقباض عروق ياي سالمندان برداخته و نشان داديند كه افزايش

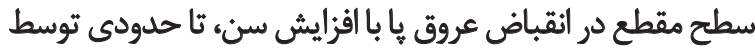

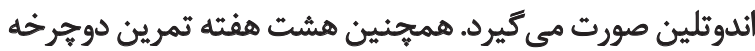

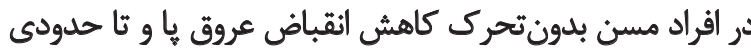

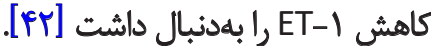

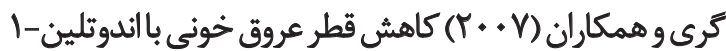

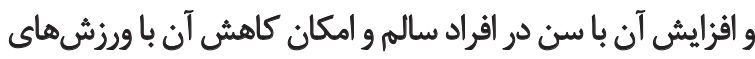

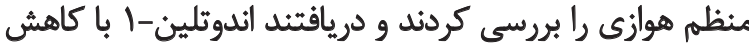

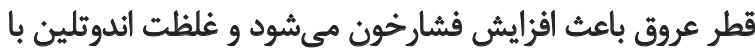

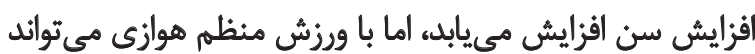

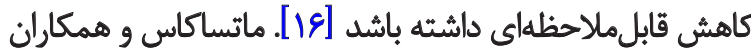

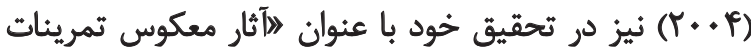

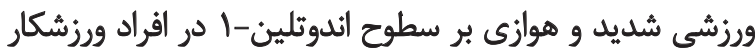

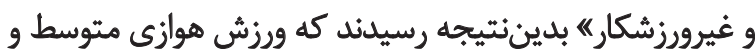

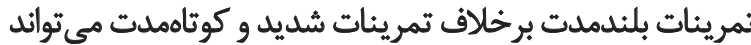

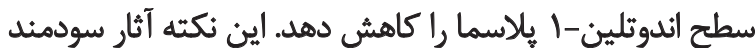

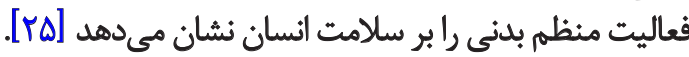

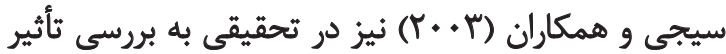

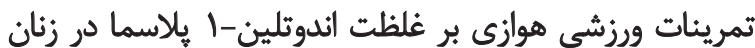

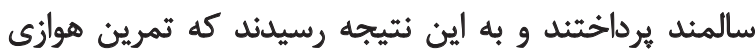

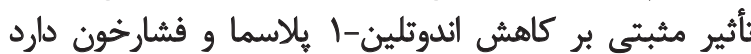

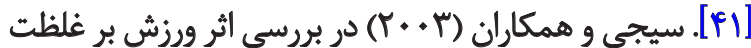

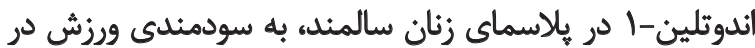

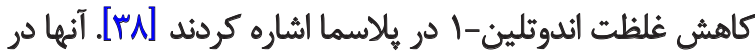

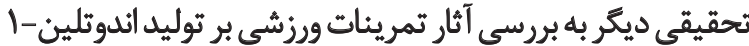

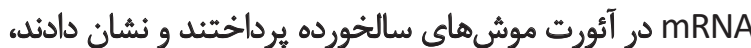

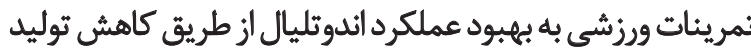

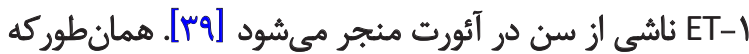

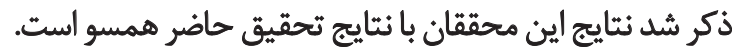
ازسوى 


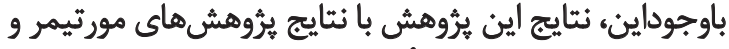

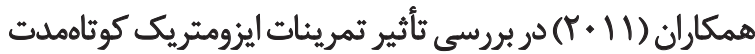

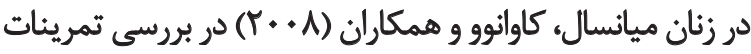

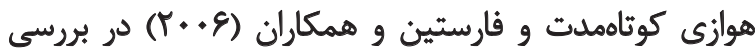

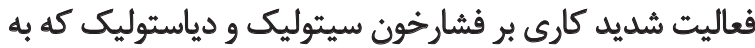

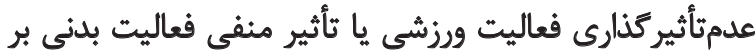

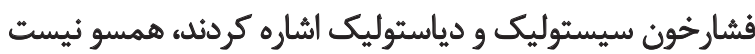

[Ir. r).rq]

اين تناقض را مىتوان نتيجه انتخاب نوع تمرين دانست؛ زيرا

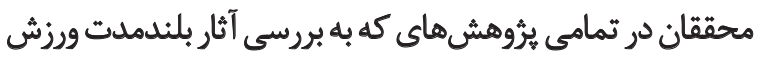

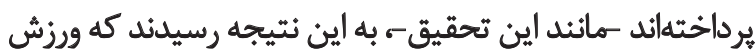

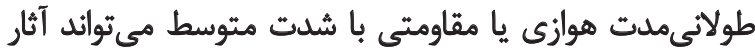

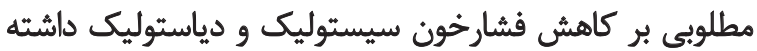

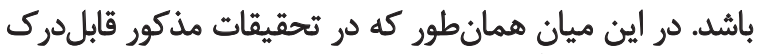

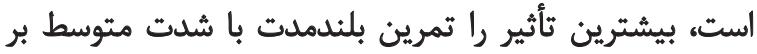
كاهش فشارخون سيستوليك و دياستوليك داشته است.

بالين حال در تحقيقاتي كه آثار حاد ورزش بررسى شده است،

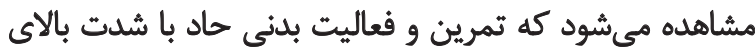

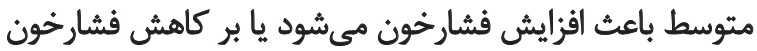

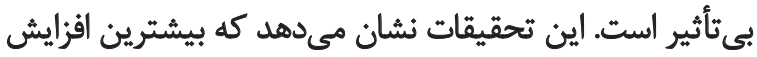

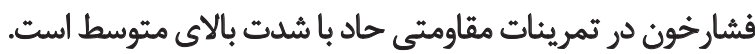

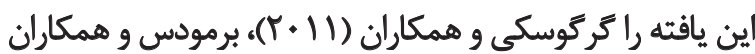

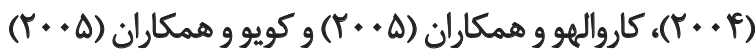

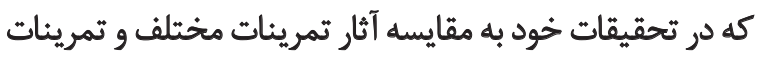

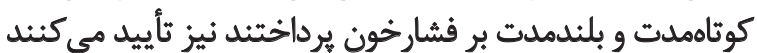

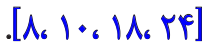

در بروهش حاضر آثار تمرين هوازى بلندمدت با شدت متوسي

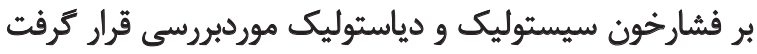

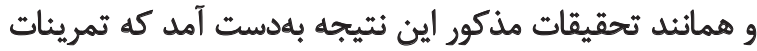

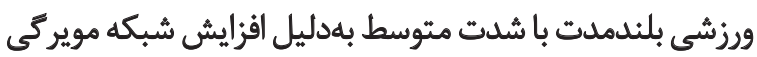

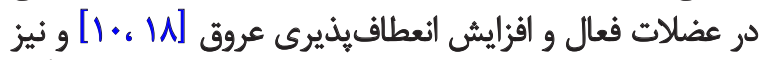

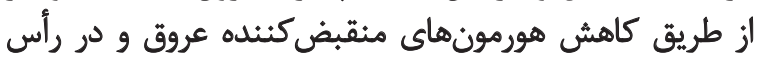

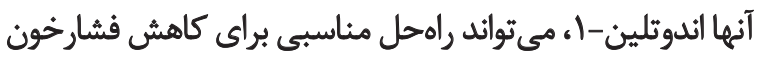

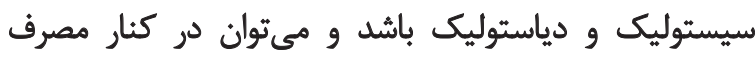

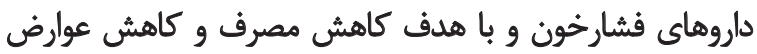

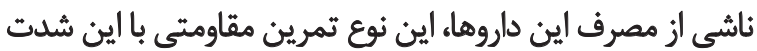

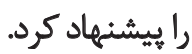

نتايج اين يُوهش نشان ميدهد كه بين تغيير غلظت بئت

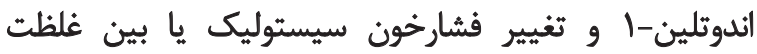

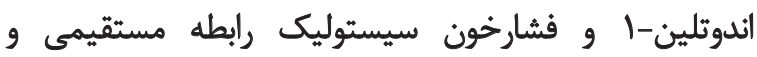

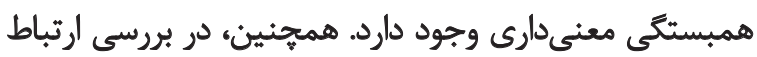

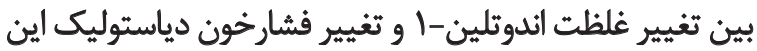

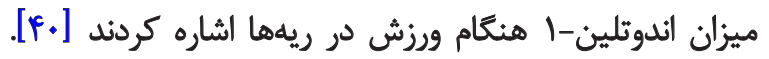

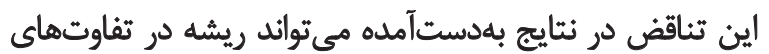

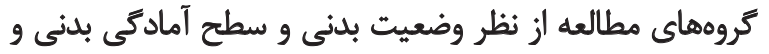

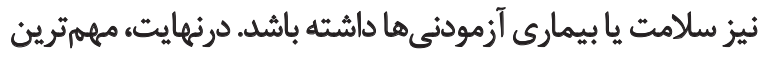

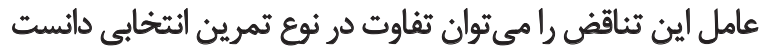

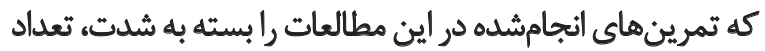

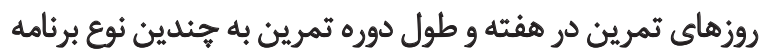

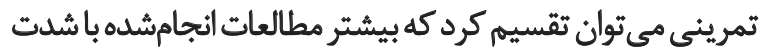

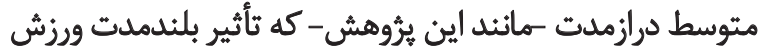
را بررسى مي كردنده باعث كاهش سطح اندوتلين - 1 بلاسما شده است.

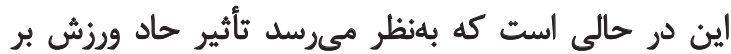

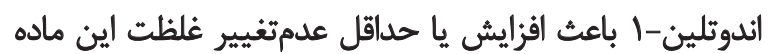

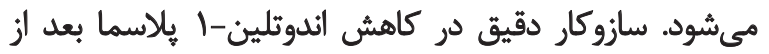

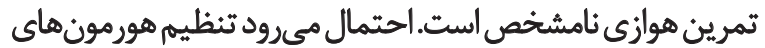

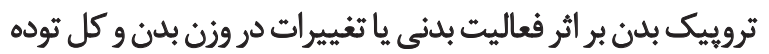

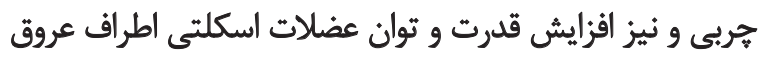

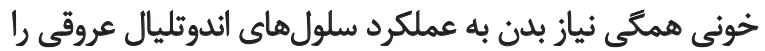

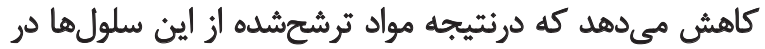

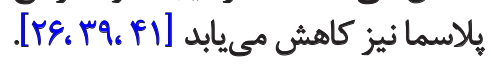
همانطوركه نتايج تحقيق حاضر نشان داد، هشت هفته تمرين

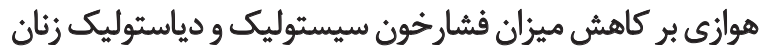

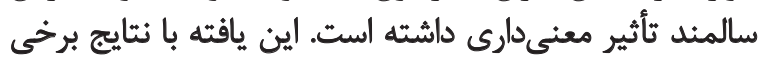

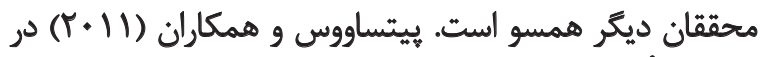

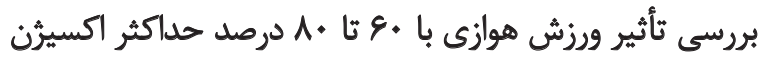

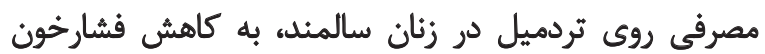

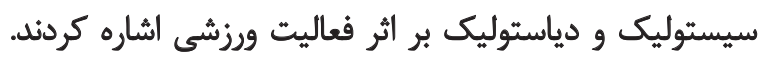

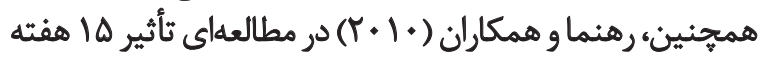

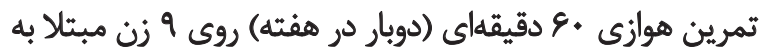

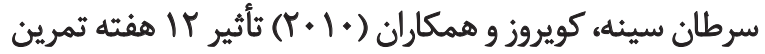

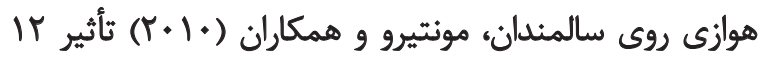

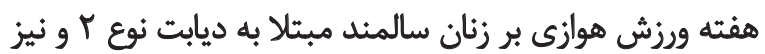

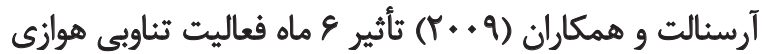

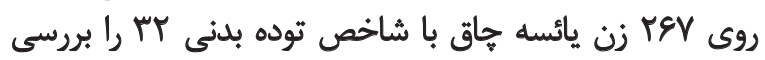

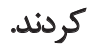

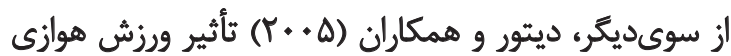

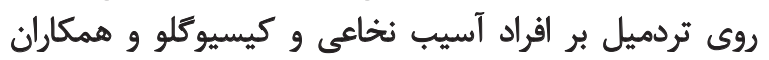

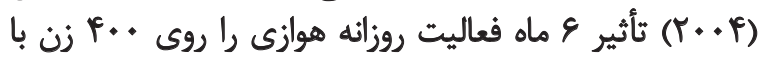

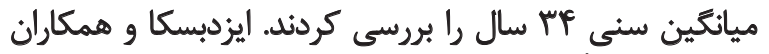

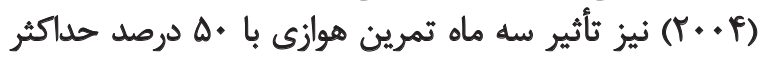

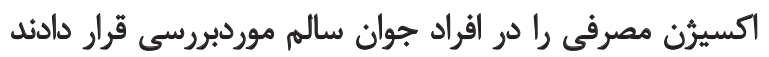

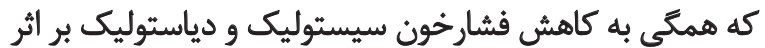

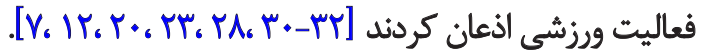




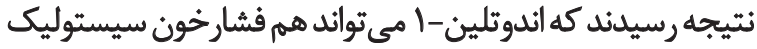

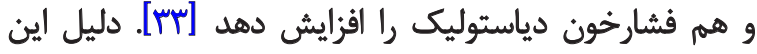

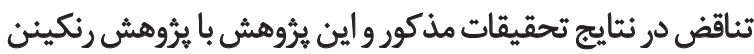

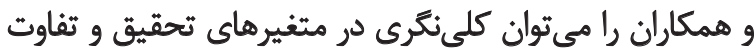

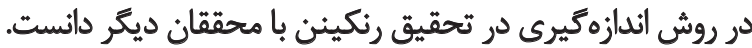

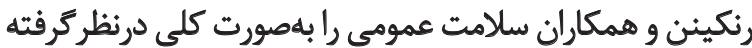

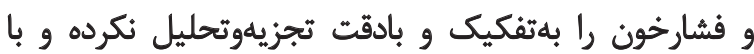

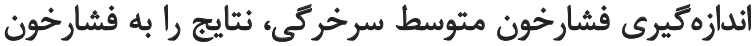
سيستوليك و دياستوليك تعميم دادهاند.

\section{نتيجليَيرى نهبايى}

بلهوركلى نتايج اين تحقيق نشان داد تمرينهاي هوازى با

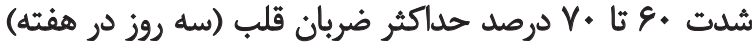

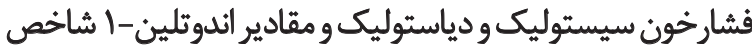

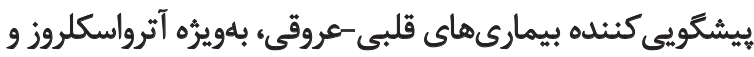

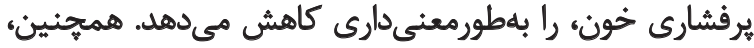

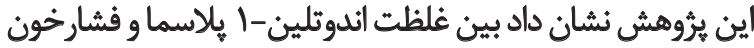

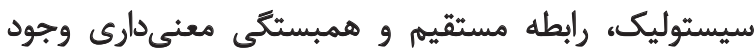
دارد و بين غلظت اندوتلين-1 يلاسما و فشارخون دياستوليك، همبستكى معنى دارى وجود ندارد.

برايناساس مىتوان كفت اندازهيرى اندوثلين-ا، روش

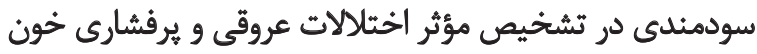

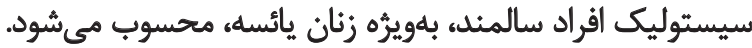

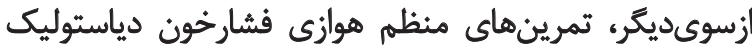

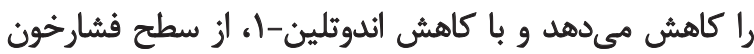

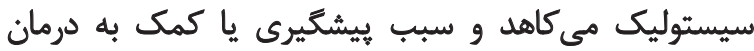

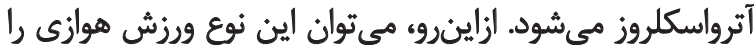

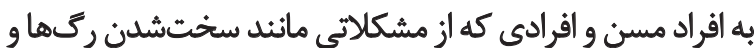

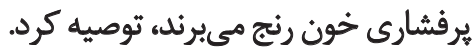

نتيجه بلهدست آمد كه همبستكى معنى دارى بين اين دو متغير يا غلظت اندوتلين-1 و فشارخون دياستوليك رابطه مستقيم

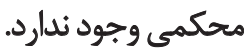

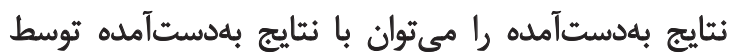

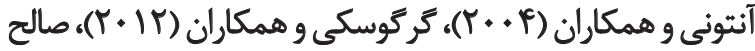

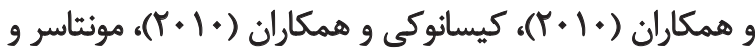

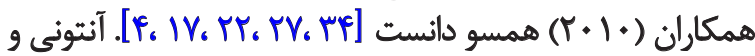

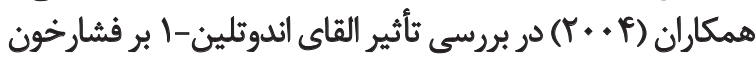

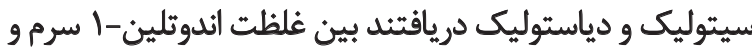

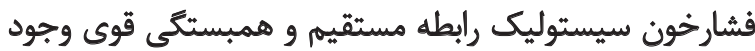

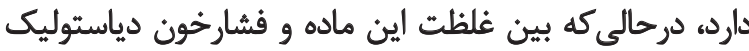

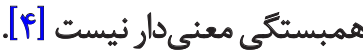

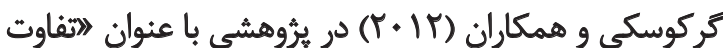

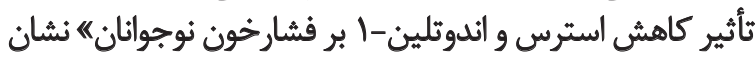

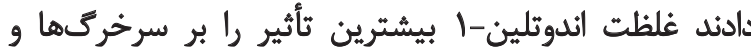

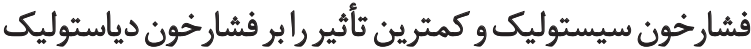

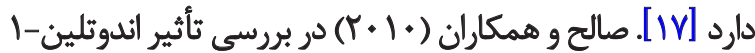

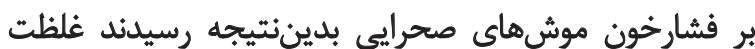

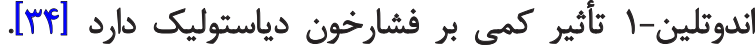

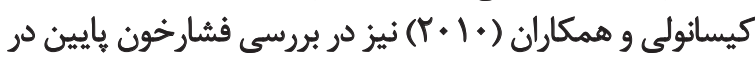

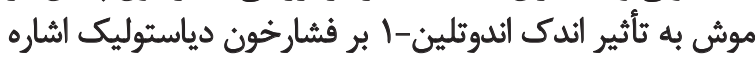

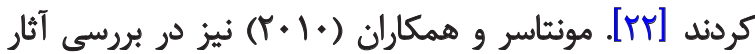

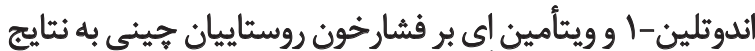

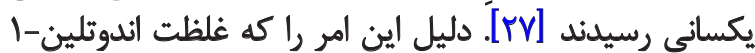

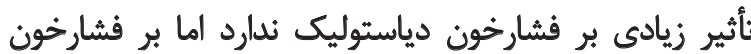

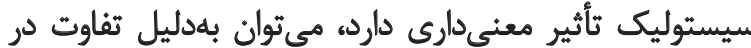

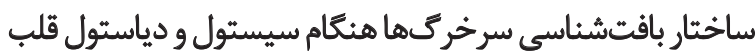

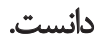

يكى از علتهاى اصلى فشارخون كه در اين تحقيق نيز

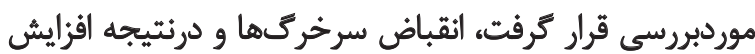

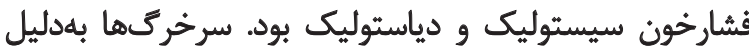

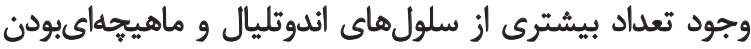

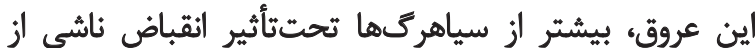

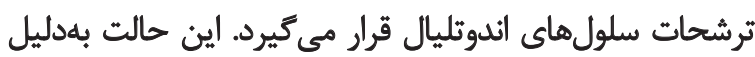

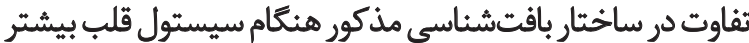

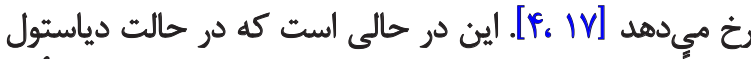

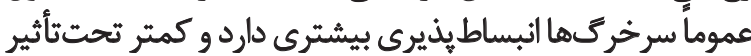

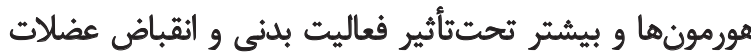
مجاور خود، منقبض مىشود.

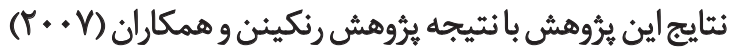

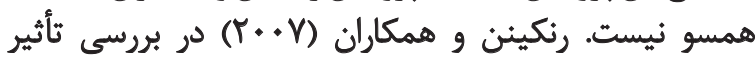

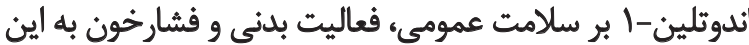




\section{References}

[1] Ahmadi Asl N, Niknazar S, Farajnia S. [Effect of three months exercise on expression of endithelin-1 mRNA in the lung tissue (Persian)]. Pharmacological Sciences. 2008; 11(1):59-62.

[2] Tosun A, Bölükbaşı N, Çıngı E, Beyazova M, Ünlü M. Acute effects of a single session of aerobic exercise with or without weightlifting on bone turnover in healthy young women. Modern Rheumatology. 2006; 16(5):300-04.

[3] Bagheri L, Salami F, Hedayati M, Reisi J. [Effect of aerobic training on estrogen, PTH, calcium, alkalinephosphatase and albumin, in postmenopausal women (Persian)]. Iranian Journal of Ageing. 2009; 4(2):26-35.

[4] Anthony J, Donato A, Delp D. The effect of aging and exercise training on endothelin-1 vasoconstrictor responses in rat skeletal muscle arterioles. Cardiovascular Research. 2004; 66(16):393-401.

[5] Jones AW, Rubin LJ, Magliola L. Endothelin-1 sensitivity of porcine coronary arteries is reduced by exercise training and is gender dependent. Journal of Applied Physiology. 1999; 87(3):1172-177.

[6] Donato AJ, Lesniewski LA, Delp MD. The effects of aging and exercise training on endothelin-1 vasoconstrictor responses in rat skeletal muscle arterioles. Cardiovascular Research. 2005: 66(2):393-401.

[7] Arsenault BJ, Côté M, Cartier A, Lemieux I, Després JP, Ross R, et al. Effect of exercise training on cardiometabolic risk markers among sedentary, but metabolically healthy overweight or obese post-menopausal women with elevated blood pressure. Atherosclerosis. 2009; 207(2):530-33.

[8] Bermudes AM, Vassallo DV, Vasquez EC, Lima EG. Ambulatory blood pressure monitoring in normotensive individuals undergoing two single exercise sessions: resistive exercise training and aerobic exercise training. Arquivos Brasileiros de Cardiologia. 2004; 82(1):57-64.

[9] Cadore EL, Pinto RS, Lhullier FL, Correa CS, Alberton CL, Pinto SS, et al. Physiological effects of concurrent training in elderly men. International Journal of Sports Medicine. 2010; 31(10):689-97.

[10] Carvalho DC, Cliquet A. Response of the arterial blood pressure of quadriplegic patients to treadmill gait training. Brazilian Journal of Medieval \& Biological Research. 2005; 38(9):1367-373.

[11] De Souza CA, Shapiro LF, Clevenger CM, Dinenno FA, Monahan KD, Tanaka H, et al. Regular aerobic exercise prevents and restores age-related declines in endothelium-dependent vasodilation in healthy men. Circulation. 2000; 102(12):1351-357.

[12] Ditor DS, Kamath MV, MacDonald MJ, Bugaresti J, McCartney N, Hicks AL. Effects of body weight-supported treadmill training on heart rate variability and blood pressure variability in individuals with spinal cord injury. Journal of Applied Physiology. 2005; 98(4):1519-525.

[13] Faerstein E, Chor D, Griep R, Alves M, Lopes C. Blood pressure measurement in the pro saude study. Cadernos de Saúde Pública. 2006; 22(9):97-102.

[14] Glaus TM, Grenacher B, Koch D, Reiner B, Gassmann M. High altitude training of dogs results in elevated erythropoietin and endothelin-1 serum levels. Comparative Biochemistry and Physiology Part A: Molecular \& Integrative Physiology. 2004; 138(3):35561.
[15] Van Guilder GP, Westby CM, Greiner JJ, Stauffer BL, DeSouza CA. Endothelin-1 vasoconstrictor tone increases with age in healthy men but can be reduced by regular aerobic exercise. International Journal of Hypertension. 2007; 50(2):403-09.

[16] Gray P, Vang G, Christian M. Endothelin-1 vasoconstrictor tone increase with age but can be reduced by exercise. International Journal of Hypertension. 2007; 21(22):403-09.

[17] Greqoski M, Barnes V, Tinqen MS, Dong Y, Zhu H, Treber F. Influences of endothelin- 1 and chronic stress exposure. International Journal of Hypertension. 2012; 57(3):57-63.

[18] Gregoski MJ, Barnes VA, Tingen MS, Harshfield GA, Treiber FA. Breathing awareness meditation and life skills training programs influence upon ambulatory blood pressure and sodium excretion among African American adolescents. Journal of Adolescent Health. 2011; 48(1):59-64.

[19] Muratli HH, Çelebi L, Hapa O, Biçimoğlu A. Comparison of plasma endothelin levels between osteoporotic, osteopenic and normal subjects. BMC Musculoskeletal Disorders. 2005; 6(1):49. doi: $10.1186 / 1471-2474-6-49$

[20] Izdebska E1, Cybulska I, Izdebskir J, Makowiecka-Ciesla M, Trzebski A. Effects of moderate physical training on blood pressure variability and hemodynamic pattern in mildly hypertensive subjects. Journal of Physiology and Pharmacology. 2004; 55(4):713-24

[21] Kawano H, Tanimoto M, Yamamoto K, Sanada K, Gando Y, Tabata I, et al. Resistance training in men is associated with increased arterial stiffness and blood pressure but does not adversely affect endothelial function as measured by arterial reactivity to the cold pressor test. Experimental Physiology. 2008; 93(2):296302.

[22] Kisanuki YY, Emoto N, Ohuchi T, Widyantoro B, Yagi K, Nakayama K, et al. Low blood pressure in endothelial cell-specific endothelin 1 knockout mice. 2010; 56(1):121-28. doi: 10.1161/hypertensionaha.109.138701

[23] Kisioglu AN, Aslan B, Ozturk M, Aykut M, Ilhan I. Improving control of high blood pressure among middle-aged Turkish women of low socio-economic status through public health training. Croatian Medical Journal. 2004; 45(4):477-82.

[24] Kou HK, Jones R, Tennstedt S, Talbot L, Morris J. Effect of blood pressure and diabetes mellitus on physical fanction in older adults. Journal of the American Geriatrics Society. 2005; 53(7):1154-161.

[25] Matsakas A, Mougios V. Opposite effect of acute aerobic exercise on plasma endothelin levels. Medical Science Monitor. 2004; 10(10):568-71.

[26] Meada S, Miyauch T, Lemitsu M, Sugawara J, Nagata Y, Goto K. Resistance exercise training reduces plasma endothelin-1. Japan Sport. 2011; 7(3):20-31.

[27] Montasser ME, Shimmin LC, Gu D, Chen J, Gu C, Kelly TN, Jaquish CE. Blood pressure response to potassium supplementation is associated with genetic variation in Endothelin 1 (EDN1) and interactions with E selectin (SELE) in rural Chinese. International Journal of Hypertension. 2010; 28(4):748-55.

[28] Monteiro LZ, Fiani CR, Freitas MC, Zanetti ML, Foss MC. Decrease in blood pressure after aerobic training in elderly women with type 2 diabetes. Arquivos Brasileiros de Cardiologia. 2010; 95(5):563-70. 
[29] Mortimer J, Andrew J. Effect of short-term isometric hand grip training on blood pressure in middle aged females. Cardiovascular Journal of Africa. 2011; 22(5):257-63.

[30] Pitsavos Ch, Chrysohoou Ch, Matina K, Christodoulos S. The impact of moderate aerobic physical training on midly hypertensive males. Hellenic Journal of Cardiology. 2011; 52:6-14.

[31] Querioz A, Kangusuku H, Forjaz C. Effects of resistance training on blood pressure in the elderly. Arquivos Brasileiros de Cardiologia. 2010; 95(1):135-40

[32] Rahnama N, Nouri R, Rahmaninia F, Damirchi A, Emami H. The effects of exercise training on maximum aerobic capacity, resting heart rate, blood pressure and anthropometric variables of postmenopausal women with breast cancer. Journal of Research in Medicine Science. 2010; 15(2):78-83.

[33] Rankinen T, Church T, Rice T, Markward N, Leon AS, Rao DC, et al. Effect of endothelin 1 genotype on blood pressure is dependent on physical activity or fitness levels. International Journal of Hypertension. 2007; 50(6):1120-125.

[34] Saleh M, Boesen EI, Pollock JS, Savin V, Pollock DM. Endothelin-1 increases blood pressure in the rat. International Journal of Hypertension. 2010; 56(5):942-49.

[35] Samanta D, Adolf S. The effect of physical exercise on endothelial function. Sport Medicine. 2009; 20:797-812.

[36] Maeda S, Otsuki T, Iemitsu M, Kamioka M, Sugawara J, Kuno $S$, et al. Effects of leg resistance training on arterial function in older men. British Journal of Sports Medicine. 2006; 40(10):867-69.

[37] Seiji M, Subina J, Motoyuki J. Weight loss reduces plasma endothelin-1. Journal of Ibaraki Japan. 2011; 1(3):305-21.

[38] Seiji M, Subrina J. Aerobic training reduces endotelin_1 concentration in old healthy women. American Physiological Society. 2003; 95(1):336-41.

[39] Maeda S, Miyauchi T, Iemitsu M, Tanabe T, Yokota T, Katsutoshi GO, et al. Effects of exercise training on expression of endothelin-1 mRNA in the aorta of aged rats. Clinical Science. 2002; 103(2002):118-123. doi: 10.1042/CS103S118S

[40] Seiji M, Takashi M, Satoshi S. Prolonged exercise causes an increase endothelin-1 production in the heart in rats. American Journal of Physiology of Heart. 275(26):2105-112.

[41] Maeda S, Tanabe T, Miyauchi T, Otsuki T, Sugawara J, Iemitsu $\mathrm{M}$, et al. Aerobic exercise training reduces plasma endothelin-1 concentration in older women. Journal of Applied Physiology. 2003; 95(1):336-41.

[42] Thijssen DH, Rongen GA, Van Dijk A, Smits P, Hopman MT. Enhanced endothelin-1-mediated leg vascular tone in healthy older subjects. Journal of Applied Physiology. 2007; 103(3):852-57.

[43] Thijssen HJ, Ellenkamp R, Kooijman M, Pickkers P. A causal role for endothelin-1 in the vascular adaptation to skeletal muscle deconditioning in spinal cord injury. Arteriosclerosis, Thrombosis, and Vascular Biology. 2007; 27(2):325-31.

[44] Williams M. Nutrition for health, fitness and sport. $6^{\text {th }}$ ed. New York: McGraw Hill; 2002. 
